\title{
ANÁLISE DO SUPRIMENTO ATUAL E POTENCIAL DE ÁGUA POTÁVEL PARA OS MUNICÍPIOS CEARENSES
}

\section{Supply Analysis Of Current And Potentil Of Water For Cearenses Cities}

\author{
José César Vieira Pinheiro \\ Prof. Dr. do Departamento de Economia Agrícola da Universidade Federal do Ceará \\ Fortaleza/CE - Brasil \\ cesar.vieira@pesquisador.cnpq.br \\ Rosemeiry Melo Carvalho \\ Profa. Dra. do Departamento de Economia Agrícola da Universidade Federal do Ceará \\ Fortaleza/CE - Brasil \\ rmelo@ufc.br \\ Kelly Silva de Freitas \\ Engenheira de Pesca pela Universidade Federal do Ceará \\ Fortaleza/CE - Brasil \\ kellyfortaleza@yahoo.com.br
}

Artigo recebido para publicação em 06/04/09 e aceito para publicação em 04/07/09

RESUMO: Este trabalho analisa a situação de suprimento de água potável para as populações que residem nas sedes dos municípios cearenses com menores e maiores IDH e, respectivamente, com maiores e menores taxas de crescimento desse índice. O principal objetivo dessa análise é identificar os principais contrastes e semelhanças entre os municípios em relação às condições de suprimento de água potável, principalmente, no que se refere a oferta atual; níveis críticos de abastecimentos; e, investimentos no setor. Os dados utilizados foram coletados junto à Agência Nacional da Água (ANA). Com base nos resultados obtidos pôde-se concluir que nos municípios com maior IDH há uma maior expectativa de satisfação no suprimento de água para o ano de 2015; apresentam uma melhor distribuição de mananciais; a gestão dos sistemas de suprimento de água é mais descentralizada; e, há uma menor freqüência de conflitos pelo uso da água. Em todos os municípios analisados, porém, a principal causa de conflitos pelo uso da água é o assoreamento dos mananciais, principalmente dos açudes.

Palavras-chaves: Água. Gestão. Ceará.

ABSTRACT: This paper analyzes the situation of supply of drinking water for residents in the seats of municipalities in Ceará with minor and major and HDI, respectively, with higher and lower rates of growth in that index. The main objective of this analysis is to identify the main contrasts and similarities between the municipalities regarding the conditions of supply of drinking water, especially with regard to the current bid; critical levels of supplies, and investments in the sector. Data were collected by the National Water Agency (ANA). Based on the results obtained it was concluded that in municipalities with the highest HDI: have a greater expectation of meeting the 
water supply for the year 2015; there is a better distribution of water sources; the management systems of water supply is more decentralized; and, there is a lower frequency of conflicts over water use. In all districts examined, however, the main cause of conflicts over water use is the silting of water sources, mainly from the reservoirs.

Keywords: Water. Management. Ceará.

\section{INTRODUÇÃO}

O Brasil está classificado pela Organização das Nações Unidas (ONU) como um País de nível intermediário em relação à renda per capita. Quanto à distribuição, tem o segundo maior índice de concentração de renda do mundo, sendo suplantado apenas por Suazilândia na África. No Brasil, 50\% das pessoas mais pobres ganham o equivalente ao que ganham $1 \%$ dos mais ricos.

Estudos realizados pelo Instituto de Pesquisa Econômica Aplicada (IPEA), com base nos dados da Pesquisa Nacional por Amostragem de Domicílios (PNAD), mostram que metade dos pobres do Brasil vive no Nordeste, sendo que o Ceará é um dos estados nordestinos com maiores problemas distributivos e por conseqüência, de exclusão social (Banco Mundial, 1999).

Uma característica marcante do Ceará é o gap entre o crescimento da sua capital, Fortaleza, e os demais municípios do Estado; a renda de quem vive no campo é praticamente $1 / 3$ da renda média no meio urbano.

De acordo com dados da PNAD, no ano 2000, o nível de desenvolvimento do Ceará, medido pelo Índice de Desenvolvimento Humano (IDH), foi de 0,7. Apesar do crescimento de $18 \%$ no valor desse índice entre 1991 e 2000, o Estado ainda ocupa a $20^{\mathrm{a}}$ posição no ranking brasileiro, sendo superado, no Nordeste, por Pernambuco e Rio Grande do Norte. Quanto ao índice de concentração de renda, o Ceará ocupa a $2^{\mathrm{a}}$ posição na região, ficando abaixo apenas de Alagoas.

Estes números demonstram que para promo- ver o desenvolvimento desse Estado faz-se necessário que haja um grande empenho do governo no sentido de implantar políticas públicas mais eficientes.

Vários estudos têm constatado que não existem possibilidades de se desenvolver economias pobres como o Ceará sem a adoção de medidas fundamentais para o provimento de infra-estrutura básica, principalmente nas áreas de saúde, educação, energia, comunicações, estradas e transporte.

Porém, a acentuada carência de condições básicas de vida, dificulta até mesmo a definição de prioridades, ou seja, o que é mais urgente para elevar a qualidade de vida da população, principalmente nas zonas rurais.

Por outro lado, dentre essas dificuldades, a escassez de água, tanto em quantidade quanto em qualidade, para a população tem se destacado como o problema mais relevante.

Considerando a importância da água para a qualidade de vida, este trabalho tem como objetivo analisar a situação de suprimento de água potável para as populações que residem nas sedes dos municípios cearenses, focalizando a situação atual e as suas perspectivas futuras.

Especificamente, analisa-se a problemática de abastecimento de água nos seguintes aspectos: características gerais dos sistemas e situação da oferta atual; necessidades de complementação de sistemas existentes, níveis críticos e conflitos de abastecimento; soluções técnicas e investimentos previstos e necessários para eliminar ou minimizar a escassez desse recurso. 
Este último aspecto é de particular interesse para os municípios mais pobres do Estado, pois, além do abastecimento de água, poderiam resultar em benefícios adicionais, a partir do desenvolvimento de projetos de infra-estrutura, com o conseqüente aumento de emprego e renda.

\section{METODOLOGIA}

\section{1. Área de Estudo}

O Estado do Ceará está localizado na região Nordeste do Brasil, limitando-se ao Norte com o Oce-

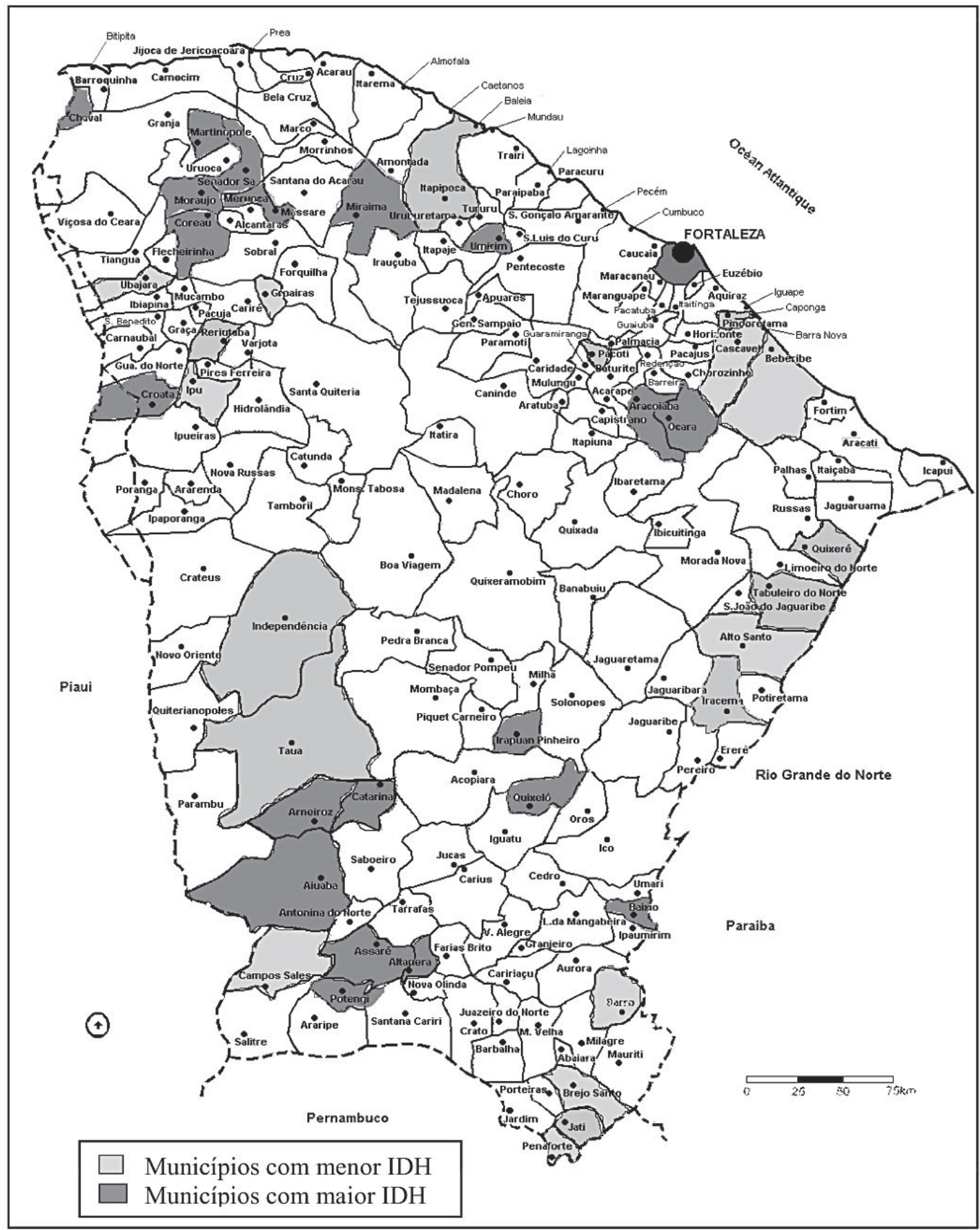

FIGURA 1. Mapa do Estado do Ceará: municípios cearenses Fonte: ANA, 2006. Adaptação dos Autores. 
ano Atlântico; ao Sul com o Estado de Pernambuco; a Leste com os Estados do Rio Grande do Norte e Paraíba e a Oeste com o Estado do Piauí.

A área total do Estado é de $148.825,6 \mathrm{~km}^{2}$, o que equivale a $9,57 \%$ da área pertencente à região Nordeste e 1,74\% da área do Brasil. Desta forma, o Estado do Ceará tem a quarta extensão territorial da região Nordeste e é o $17^{\circ}$ entre os estados brasileiros em termos de superfície territorial.

O Estado tem 184 municípios, com um contingente populacional estimado de, aproximadamente, 8.450.527 habitantes (IBGE, 2008) e um Produto Interno Bruto (PIB) de mais de $\mathrm{R} \$ 45$ bilhões de reais, $\mathrm{o}$ que coloca o Ceará como a segunda maior economia da região Nordeste do Brasil.

Dos 184 municípios cearenses, foram selecionados os 40 com maior IDH e os 40 com menor IDH, em 1991, e escolheu-se de cada um destes grupos os $20 \mathrm{mu}-$ nicípios que tiveram, respectivamente, a maior taxa de crescimento (Grupo A) - excluídos os municípios da área metropolitana de Fortaleza - e a menor taxa de crescimento de IDH (Grupo B), no período de 1991 - 2000.

Os municípios incluídos no grupo Grupo A foram: Beberibe, Cascavel, Pindoretama, Campos Sales, Tauá, Independência, Ubajara, Groaíras, Itapipoca, Pacoti, Barro, Jati, Penaforte, Brejo Santo, Ipu, Reriutaba, Quixeré, Tabuleiro do Norte, Alto Santo e Iracema. Por outro lado o Grupo B é composto por: Chaval, Quixelô, Irapuan Pinheiro, Croatá, Baixio, Ocara, Aracoiaba, Altaneira, Assaré, Potengí, Aiuaba, Arneiroz, Catarina, Coreaú, Massapé, Martinópole, Moraújo, Senador Sá, Umirim e Miraíma (FIG. 1).

Em um estudo similar Monteiro (2002) identificou os trinta municípios cearenses com maior carência de água potável, dentre esses, oito, apresentam os menores IDH incluídos na amostra selecionada. No entanto, se considerarmos os sessenta com maior escassez desse recurso, o número de municípios com menores IDH aumentam para 15, evidenciando a importância da disponibilidade de água potável para o desenvolvimento humano.

\subsection{Fonte dos Dados e Método de Análise}

Para fins de estudo foram considerados apenas os municípios cearenses incluídos no Atlas da Agência Nacional da Água (ANA), o qual apresenta dados referentes aos Estados da região Nordeste e as bacias dos rios São Francisco, Pardo, Mucuri e Jequitinhonha, situadas em Minas Gerais.

Ele foi elaborado com o objetivo de identificar e propor alternativas técnicas com garantia hídrica para atender as atuais e futuras demandas por água da população urbana e da área de abrangência, sendo composto por diversos estudos (estimativa de demandas, análise de recursos hídricos superficiais e subterrâneos, avaliação de sistemas de produção de água, arranjo institucional, etc.) que dão suporte à definição de alternativas técnicas.

O Atlas disponibiliza informações sobre, aproximadamente, 1.300 localidades, compreendendo as sedes municipais, com população urbana superior a 5.000 habitantes, bem como aquelas localizadas na área de influência de sistemas integrados, com menor contingente populacional.

O critério de análise utilizado nesse estudo baseia-se no princípio da "comparabilidade". Segundo Hendriken e Van Breda (1999) esse atributo permite que os usuários identifiquem adequadamente as semelhanças e diferenças entre dois conjuntos de fenômenos socioeconômicos.

Com base na amostra selecionada procurouse identificar os principais contrastes e semelhanças entre municípios cearenses que apresentaram os mais elevados e os mais baixos IDH, em relação às condições de suprimento de água potável, principalmente, no que se refere a: oferta atual; níveis críticos de abastecimentos e investimentos no setor.

Os dados referentes aos municípios selecionados foram submetidos a uma análise tabular de relações, tendo como variável de controle o IDH, a qual permitiu focalizar, prioritariamente, os padrões de suprimento de água, de modo que ficassem explícitas, 
acentuadas e realçadas as diferenças dos municípios sob a ótica dos seus sistemas de suprimento de água.

Seguindo a metodologia proposta por Capra (2005), nessa análise foram utilizados alguns indicadores quantitativos, embora maior ênfase tenha sido dada à tentativa de se identificar relações entre as variáveis disponíveis na busca de padrões

\section{RESULTADOS E DISCUSSÃO}

\subsection{Caracterização dos Municípios}

Os municípios selecionados na amostra representam $21,35 \%$ da área territorial do Estado e 10,54\% da população cearense. Sendo que, os municípios do grupo A ocupam uma área equivalente a 13,22\% do

TABELA 1. Características gerais dos municípios selecionados.

\begin{tabular}{|c|c|c|c|c|c|}
\hline Municípios & Área $\left(\mathrm{km}^{2}\right)$ & Área (\%) & $\begin{array}{c}\text { População Estimada } \\
(2007)\end{array}$ & $\begin{array}{c}\text { População Estimada } \\
(\%)\end{array}$ & $\begin{array}{c}\text { Precipitação } \\
\text { Pluviométrica }(\mathrm{mm})\end{array}$ \\
\hline Ceará & $148.825,60$ & 21,3479 & 8.450 .527 & 10,5405 & - \\
\hline Grupo A & 19678,9 & 13,2228 & 604.971 & 7,1590 & 921,925 \\
\hline Alto Santo & $1.338,74$ & 0,8995 & 19.154 & 0,2267 & 834,8 \\
\hline Barro & 709,655 & 0,4768 & 20.763 & 0,2457 & 934,3 \\
\hline Beberibe & $1.616,39$ & 1,0861 & 46.155 & 0,5462 & 914,1 \\
\hline Brejo Santo & 661,959 & 0,4448 & 39.613 & 0,4688 & 895,8 \\
\hline Campos Sales & $1.082,77$ & 0,7275 & 25.553 & 0,3024 & 670 \\
\hline Cascavel & 837,967 & 0,5631 & 63.932 & 0,7565 & $1.331,7$ \\
\hline Gruaíras & 155,963 & 0,1048 & 9.456 & 0,1119 & 904,5 \\
\hline Independência & $3.218,64$ & 2,1627 & 25.413 & 0,3007 & 608,4 \\
\hline Ipu & 630,468 & 0,4236 & 39.438 & 0,4667 & 903,6 \\
\hline Iracema & 822,833 & 0,5529 & 14.313 & 0,1694 & 790,4 \\
\hline Itapipoca & $1.614,68$ & 1,0849 & 107.281 & 1,2695 & $1.134,4$ \\
\hline Jati & 312,584 & 0,2100 & 7.270 & 0,0860 & 668,6 \\
\hline Pacoti & 111,959 & 0,0752 & 11.079 & 0,1311 & $1.558,1$ \\
\hline Penaforte & 190,428 & 0,1280 & 7.715 & 0,0913 & 668,6 \\
\hline Pindoretama & 72,855 & 0,0490 & 17.743 & 0,2100 & 930,7 \\
\hline Quixeré & 616,825 & 0,4145 & 18.652 & 0,2207 & 857,7 \\
\hline Reriutaba & 383,119 & 0,2574 & 19.310 & 0,2285 & 957,3 \\
\hline Tab.do Norte & 861,838 & 0,5791 & 28.291 & 0,3348 & 794,8 \\
\hline Tauá & $4.018,190$ & 2,6999 & 54.271 & 0,6422 & 597,2 \\
\hline Ubajara & 421,037 & 0,2829 & 29.569 & 0,3499 & $1.483,5$ \\
\hline Grupo B & $12.092,225$ & 8,1251 & 285.756 & 3,3815 & 874,8 \\
\hline Aiuaba & $2.434,41$ & 1,6357 & 15.585 & 0,1844 & 562,4 \\
\hline Altaneira & 73,296 & 0,0492 & 6.417 & 0,0759 & 974,3 \\
\hline Aracoiaba & 656,532 & 0,4411 & 24.423 & 0,2890 & $1.010,3$ \\
\hline Arneiroz & $1.066,43$ & 0,7166 & 7.302 & 0,0864 & 582,1 \\
\hline Assaré & $1.116,32$ & 0,7501 & 21.616 & 0,2558 & 680,7 \\
\hline Baixio & 146,442 & 0,0984 & 5.780 & 0,0684 & 741,5 \\
\hline Catarina & 486,859 & 0,3271 & 17.028 & 0,2015 & 645,2 \\
\hline Chaval & 238,228 & 0,1601 & 12.215 & 0,1445 & $1.081,2$ \\
\hline Coreaú & 775,746 & 0,5212 & 21.171 & 0,2505 & 992,1 \\
\hline Croatá & 700,356 & 0,4706 & 17.317 & 0,2049 & 599,6 \\
\hline Martinópole & 298,948 & 0,2009 & 10.304 & 0,1219 & $1.302,1$ \\
\hline Massapé & 571,531 & 0,3840 & 33.256 & 0,3935 & 749,5 \\
\hline Miraíma & 699,588 & 0,4701 & 12.131 & 0,1436 & 897,5 \\
\hline Moraújo & 415,614 & 0,2793 & 8.005 & 0,0947 & $1.060,5$ \\
\hline Ocara & 756,366 & 0,5082 & 23.359 & 0,2764 & 959,5 \\
\hline Potengi & 338,723 & 0,2276 & 9.670 & 0,1144 & 682,7 \\
\hline Quixelô & 559,760 & 0,3761 & 15.708 & 0,1859 & 806,5 \\
\hline Senador Sá & 430,580 & 0,2893 & 6.274 & 0,0742 & $1.018,8$ \\
\hline Umirim & 326,496 & 0,2194 & 18.195 & 0,2153 & $1.274,5$ \\
\hline
\end{tabular}

Fonte: IPECE, 2009. 
total, enquanto os do grupo B ocupam $8,13 \%$. A participação percentual do contingente populacional do grupo A $(7,16 \%)$ também é mais elevada do que a do grupo B (3,38\%). Deve-se ressaltar, porém, que a menor participação percentual do grupo $\mathrm{B}$, deve-se, em parte, à falta de informações, tanto de área quanto de população, para o município de Irapuan Pinheiro, pertencente a esse grupo. Os municípios dos dois grupos localizam-se, predominantemente, na região semi- árida do Estado, sendo que, no grupo A, a precipitação pluviométrica anual média histórica, $921,93 \mathrm{~mm}$, é superior a do grupo B, $874,8 \mathrm{~mm}$ (TAB. 1 e TAB. 2).

A FIG. 2 mostra a distribuição dos municípios cearenses de acordo com cinco diferentes tipos de climas: tropical quente semi-árido; tropical quente semiárido brando; tropical quente subumido; tropical quente úmido; e, tropical subquente úmido.

TABELA2. Tipos climáticos dos municípios selecionados.

\begin{tabular}{|c|c|c|}
\hline Tipos de Clima & Municípios do Grupo A & Municípios do Grupo B \\
\hline Tropical quente semi-árido & $\begin{array}{l}\text { Alto Santo } \\
\text { Barro } \\
\text { Beberibe } \\
\text { Brejo Santo } \\
\text { Campos Sales } \\
\text { Gruaíras } \\
\text { Independência } \\
\text { Ipu } \\
\text { Iracema } \\
\text { Itapipoca } \\
\text { Jati } \\
\text { Penaforte } \\
\text { Quixeré } \\
\text { Reriutaba } \\
\text { Tabuleiro do Norte } \\
\text { Tauá }\end{array}$ & $\begin{array}{l}\text { Aiuaba } \\
\text { Altaneira } \\
\text { Aracoiaba } \\
\text { Arneiroz } \\
\text { Assaré } \\
\text { Baixio } \\
\text { Catarina } \\
\text { Coreaú } \\
\text { Martinópole } \\
\text { Massapê } \\
\text { Miraíma } \\
\text { Moraújo } \\
\text { Ocara } \\
\text { Potengi } \\
\text { Quixelô } \\
\text { Senador Sá } \\
\text { Umirim }\end{array}$ \\
\hline Tropical quente semi-árido brando & $\begin{array}{l}\text { Beberibe } \\
\text { Brejo Santo } \\
\text { Ipu } \\
\text { Cascavel } \\
\text { Iracema } \\
\text { Itapipoca } \\
\text { Jati } \\
\text { Penaforte } \\
\text { Pindoretama } \\
\text { Reriutaba }\end{array}$ & $\begin{array}{l}\text { Aracoiaba } \\
\text { Chaval } \\
\text { Coreaú } \\
\text { Croatá } \\
\text { Martinópole } \\
\text { Massapê } \\
\text { Moraújo } \\
\text { Potengi } \\
\text { Senador Sá } \\
\text { Umirim }\end{array}$ \\
\hline Tropical quente subúmido & $\begin{array}{l}\text { Ipu } \\
\text { Pacoti } \\
\text { Pindoretama } \\
\text { Reriutaba } \\
\text { Ubajara }\end{array}$ & $\begin{array}{l}\text { Aracoiaba } \\
\text { Coreaú }\end{array}$ \\
\hline Tropical Quente Úmido & $\begin{array}{l}\text { Ipu } \\
\text { Pacoti } \\
\text { Reriutaba }\end{array}$ & Massapê \\
\hline Tropical sub quente úmido & $\begin{array}{l}\text { Ipu } \\
\text { Reriutaba }\end{array}$ & \\
\hline
\end{tabular}

Fonte: IPECE, 2009. 


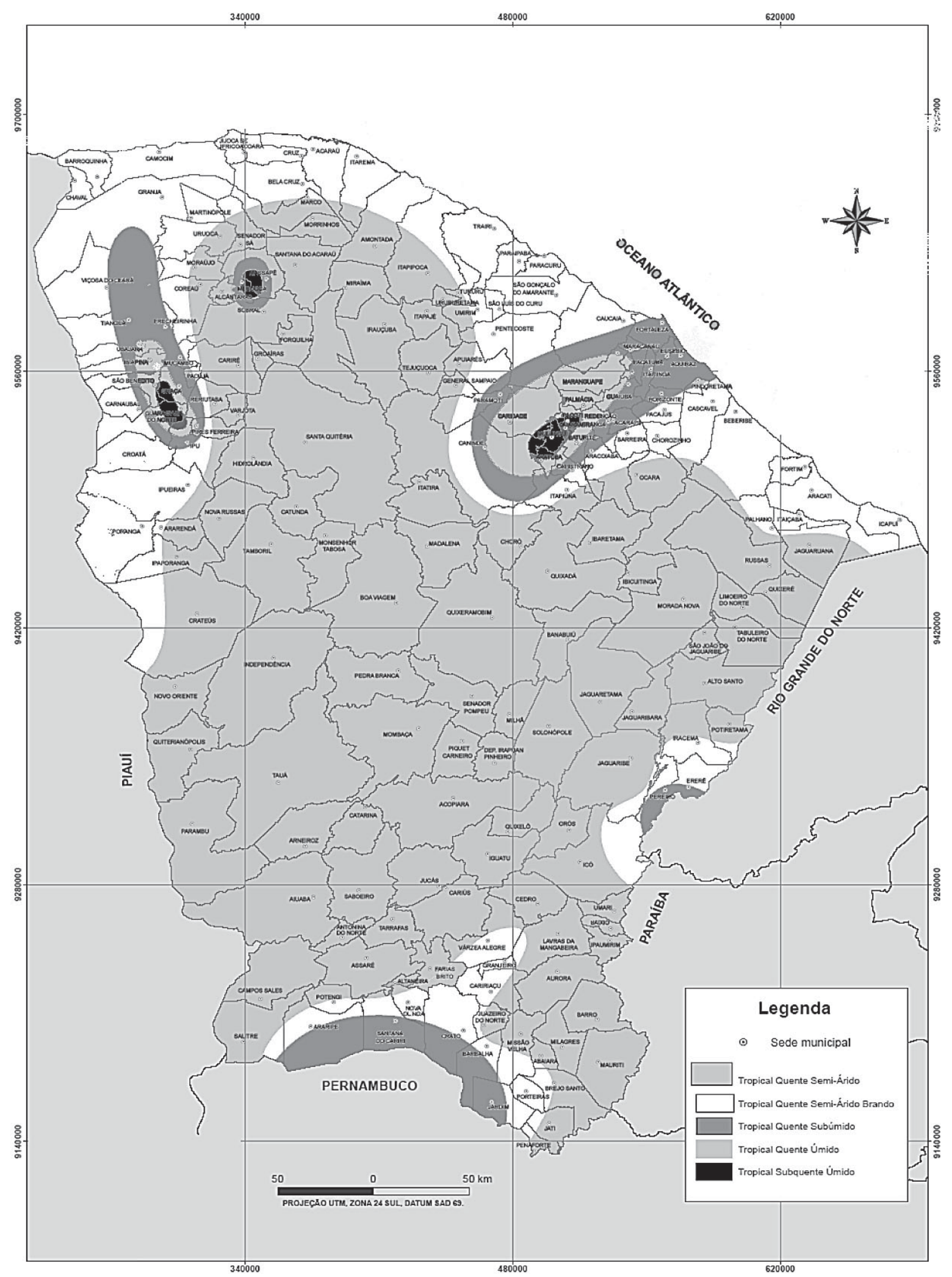

FIGURA 2. Mapa do Estado do Ceará: tipos de climáticos Fonte: IPECE, 2009. 


\subsection{Sistemas de Abastecimento de Água dos Municípios}

Inicialmente, deve-se ressaltar que, os municípios do grupo A têm maior participação no estudo da Agencia Nacional de Águas (ANA), chegando a aproximadamente $85 \%$. Por outro lado, dos municípios do Grupo B, 40\% foram excluídos porque, o estudo da ANA considera apenas as sedes municipais com mais de 5.000 habitantes, dificultando e limitando a possibilidade de investimentos em suprimento de água nos municípios mais pobres.

Na TAB. 3 e TAB. 4 são apresentados os principais recursos hídricos de cada município nos grupos $\mathrm{A}$ e B, respectivamente. No grupo A em apenas quatro municípios não há açudes. Nesses municípios os recursos hídricos originam-se de poços, e, em Reriutaba há também uma adurora. Enquanto que, no grupo $\mathrm{B}$ apenas dois municípios, Baixio e Croatá, dispõem apenas de poços.

TABELA 3. Recursos hídricos dos municípios do grupo A.

\begin{tabular}{|c|c|}
\hline Municipios & Recursos Hidricos \\
\hline Alto Santo & $\begin{array}{l}\text { Açudes Castanhão e Taborda (Médio/ Baixo Jaguaribe), Eixo de integração Castanhão / RMF/ Trecho I } \\
\text { (Açude Castanhão) e } 82 \text { poços }\end{array}$ \\
\hline Barro & Açudes Tavares e Prazeres (bacia do rio salgado), 2 adutoras e 79 poços \\
\hline Beberibe & Açude Medeiros, Eixo de integração Pirangui/Lagoa do Uruaú (rio Pirangui), 3 adutoras e 133 poços \\
\hline Brejo Santo & Açude Atalho (Bacia do Rio Salgado) e 189 poços \\
\hline Campos Sales & Açude Poço da Pedra (Bacia do alto Jaguaribe), 2 adutoras e 147 poços \\
\hline Cascavel & $\begin{array}{l}\text { Açude Malcozinhado (Bacia Metropolitana), Eixo de intregração Canal do Trabalhador (Rio Jaguaribe), } 1 \\
\text { adutora e } 253 \text { poços }\end{array}$ \\
\hline Gruaíras & Açude Córrego, 1 adutora e 41 poços \\
\hline Independência & $\begin{array}{l}\text { Açudes Cupim, Moleque, Jaburu II, Logradouro I, Pedra D’ água I e Barra Velha ( Rio Parnaíba), } 1 \\
\text { adutores e } 260 \text { poços }\end{array}$ \\
\hline Ipu & Açudes Riacho Fundo e Bonito, 1 adutora e 45 poços \\
\hline Iracema & Açudes Santo Antônio, Ema e Canafístula ( Médio/ Baixo Jaguaribe), 1 adutora e 35 poços \\
\hline Itapipoca & Açudes Poço Verde, Mulungu e Quandu (Bacia do Litoral), 1 adutora e 125 poços \\
\hline Jati & Açude Joãozinho e 43 poços \\
\hline Pacoti & Açudes Alto Alegre e Formosa, rio Pacoti e 45 poços \\
\hline Penaforte & 33 poços \\
\hline Pindoretama & 23 poços \\
\hline Quixeré & 82 poços \\
\hline Reriutaba & 1 adutora e 21 poços \\
\hline Tabuleiro do Norte & Açude Olho D’ água, 1 adutora e 136 poços \\
\hline Tauá & $\begin{array}{l}\text { Açudes Brôco, Cachoeira I, Ingá, Mutuquinha, Santa Teresa, Trici, Favelas, Várzea do Boi e Forquilha II, } \\
1 \text { adutores e } 300 \text { poços }\end{array}$ \\
\hline Ubajara & Açude Jaburu I e 53 poços \\
\hline
\end{tabular}

Fonte: IPECE, 2009. 
Análise do suprimento atual e potencial de água potável para os Municípios cearenses José César Vieira Pinheiro, Rosemeiry Melo Carvalho, Kelly Silva de Freitas

TABELA 4. Recursos hídricos dos municípios do grupo B.

\begin{tabular}{|c|c|}
\hline Municipios & Recursos Hidricos \\
\hline Aiuaba & Açude Benquê (Alto Jaguaribe), 1 adutora e 63 poços \\
\hline Altaneira & Açude Valério (Alto Jaguaribe) e 33 poços \\
\hline Aracoiaba & Açude Aracoiaba ( região metropolitana), 3 adutoras e 158 poços \\
\hline Arneiroz & Açude Arneiroz II e 68 poços \\
\hline Assaré & Açude Canoas (Alto Jaguaribe ), 1 adutora e 73 poços \\
\hline Baixio & 33 poços \\
\hline Catarina & Açudes Rivaldo Carvalho e Bueno Aires, 1 adutora e 41 poços \\
\hline Chaval & Açudes Novo e Itaúna (Coreaú), 2 adutoras e 11 poços \\
\hline Coreaú & Açudes de Trapiá III, Diamante, Angicos (Coreaú) e Brequedofe e 87 poços \\
\hline Croatá & 62 poços \\
\hline Martinópole & Açude Martinópole (bacia do rio Coreaú), 1 adutora e 44 poços \\
\hline Massapé & Açude Acaraú, Mirim (bacia do rio Acaraú), 2 adutoras, rios Acaraú e Tucunduba e 119 poços \\
\hline Miraíma & Açude São Pedro do Timbaú (Bacia Litoral) e 50 poços \\
\hline Moraújo & Açude Várzea da Volta (bacia do Coreaú) e 42 poços \\
\hline Ocara & Açude Novas Vidas, 1 adutora e 108 poços \\
\hline Potengi & Açude Pau Preto, rio Ipueiras, 56 poços \\
\hline Quixelô & Açude Falé e 85 poços \\
\hline Senador Sá & Açude Tucunduba (Coreaú), 1 adutora e 23 poços \\
\hline Umirim & Açudes São Joaquim II, Frios (rio Curu) e 21 poços \\
\hline
\end{tabular}

Fonte: IPECE, 2009.

No grupo A, os municípios têm uma maior descentralização administrativa dos sistemas de suprimento de água, tendo a participação da prefeitura na sua gestão e de representações de algumas comunidades; no grupo B, todos os sistemas são geridos por um órgão estadual, a Cagece, caracterizando um alto grau de centralização (TAB. 5).

O sexto fundamento da Lei 9433 estabelece que a gestão dos recursos hídricos deve ser descentralizada e contar com a participação do Poder Público, dos usuários e principalmente, das comunidades porque estas naturalmente conhecem melhor os seus problemas e peculiaridades. Esse fundamento tem por base a premissa de que não se deve levar a uma decisão superior o que pode ser solucionado em uma hierarquia inferior e isto só será possível com o pleno funcionamento dos comitês de bacias (Campos \& Studart, 2001).

Com base nesses aspectos, pode-se inferir que, a centralização de recursos e de políticas públicas em órgãos estaduais, com a exclusão, ou pequena participação das representações locais, não é o melhor modelo de gestão. Assim, embora o órgão estadual conheça os problemas mais abrangentes, este não deve prescindir de uma ação conjugada com o poder local através de uma gestão compartilhada. 
Análise do suprimento atual e potencial de água potável para os Municípios cearenses

José César Vieira Pinheiro, Rosemeiry Melo Carvalho, Kelly Silva de Freitas

TABELA 5. Características gerais dos sistemas de abastecimento de água dos municípios do Estado do Ceará, 2006.

\begin{tabular}{lcc}
\hline Aspectos Analisados dos Municípios & Grupo A (\%) & Grupo B (\%) \\
\hline Cadastrados & 85 & 60 \\
Pertencentes ao Semi-Árido & 82 & 67 \\
Suprimento satisfatório até 2015 & 35 & 25 \\
Prestador de serviço - prefeituras & 18 & 0 \\
Mananciais - Poços & 29 & 17 \\
Mananciais - Açude /Lagoa & 53 & 75 \\
Mananciais - Rio & 17 & 8 \\
\hline
\end{tabular}

Fonte: Elaborada pelos autores com base nos dados da Agencia Nacional de Águas, 2006.

\subsection{Conflitos nos Sistemas deAbastecimento de Água}

As necessidades de complementação das fontes de suprimento de água são similares entre os dois grupos. No entanto, a tendência de ocorrência de conflitos quanto à utilização do uso da água são maiores no grupo $\mathrm{B}$, devido, principalmente, a sua maior escassez (TAB. 6).

As principais causas dos conflitos pela água, de acordo com sua ordem de importância, são: o assoreamento de rios e açudes; assoreamento e mineração; assoreamento e agrotóxico.

O assoreamento diminui a vazão dos rios, reduzindo, portanto, a disponibilidade hídrica. Segundo Lima et al. (2008), o assoreamento da grande maioria dos corpos de água cearenses estão associadas a práticas agrícolas inadequadas nas lavouras de subsistência, tais como o desmatamento das margens dos rios $\mathrm{e}$ o uso indiscriminado de queimadas que prejudicam a fertilização dos solos e favorecem a erosão. Com os solos desprotegidos, a água que deveria percolar e alimentar o lençol freático torna-se veículo de sedimentos para o leito dos rios e riachos, diminuindo a vazão e carreando sedimentos para os reservatórios.

Dados da diretoria de pesquisa do $\mathrm{IBGE}^{1}$ informam que $44 \%$ dos municípios brasileiros revelaram problemas de assoreamento dos rios como a principal causa de prejuízos da atividade pesqueira e os principais Estados prejudicados foram o Ceará, R. G. do Norte e Bahia.
Assim, a gestão dos recursos naturais no âmbito de determinadas unidades geoambientais, tais como as microbacias hidrográficas e a organização produtiva, devem ser tarefas coletivas, pois somente a partir de um projeto participativo e negociado será possível fazer com que cada comunidade defina como coletar e armazenar a água de escoamento, plantio de espécies nativas em nascentes, reposição de mata ciliar, cuidados com a área de recarga dos mananciais, implantar cordões de vegetação e obras civis que impeçam o assoreamento e as diferentes formas de erosão.

Adicionalmente, deve-se definir: área de plantio e o uso do solo; como escolher as lavouras e os tipos de produção animal; e o destino dos seus produtos. Para tanto, será necessário que cada microbacia ou conjunto de microbacias hidrográficas conte com consórcios ou associações que concebam e promovam as intervenções necessárias tanto em termos institucionais e organizacionais quanto no aspecto tecnológico. A dificuldade reside no fato de serem ações sem retorno imediato, contrariando a cultura imediatista predominante.

As fontes de conflitos decorrentes da combinação de assoreamentos com as demais causas (mineração, agrotóxico e outros) são menos freqüentes no grupo B. Os municípios desse grupo, no entanto, não se ressentem do uso de agrotóxico, pois, em geral, os produtores agrícolas não dispõem de muitos recursos para a aquisição desse produto nas quantidades requeridas, uma vantagem em termos ambientais. 
TABELA 6. Causas de conflitos nos sistemas de abastecimento d'água nos grupos de municípios com maiores e menores IDH's do Estado do Ceará, 2006.

\begin{tabular}{lcc}
\hline Aspectos Analisados dos Municípios & Grupo A(\%) & Grupo B (\%) \\
\hline Necessidade de complementação do manancial & 68 & 66 \\
Existe conflito de uso & 69 & 83 \\
Fonte de conflito: Assoreamento & 75 & 80 \\
Fonte de conflito: Assoreamento + Mineração & 8 & 6 \\
Fonte de conflito: Assoreamento + Agrotóxico & 10 & 0 \\
Fonte de conflito: Assoreamento + Agrotóxico + mineração & 5 & 2 \\
Fonte de conflitos: Assoreamento + irrigação + Agrotóxico + mineração & 0 & 12 \\
Fonte de conflitos: Assoreamento + irrigação + Agrotóxico + mineração + outras razões & 2 & 0 \\
\hline
\end{tabular}

Fonte: Elaborada pelos autores com base nos dados da Agencia Nacional de Águas, 2006.

\subsection{Projeto dos Sistemas de Abastecimento de Água dos Municípios}

Entre os dezessete municípios do Grupo A incluídos no Atlas da ANA, apenas nove têm informações relacionadas sobre o projeto dos sistemas de abaste-cimento de água dos municípios (TAB. 7). Nesses municípios, mais de $80 \%$ dos mananciais são açudes, com vazões variando de 110 a 480 litros por segundo (1/seg). A maioria tem água de boa qualidade, sendo que, as restrições ocorrem apenas nos açudes Poço da Pedra e Barra Velha que abastecem respectivamente as sedes municipais de Campos Sales e Independência.
As alterações de regimes de vazões ocorrem com maior importância no açude Triçí (29\%) que abastece Tauá e açude Malcozinhado (21\%) que abastece Beberibe e Cascavel.

A captação nos açudes é do tipo flutuante, com vazão média de 47 1/seg. As informações referentes à potência dos conjuntos de motobombas $(\mathrm{CV})$, comprimentos das adutoras de água bruta e tratada (m) e capacidade das estações de tratamento são fundamentais para se estimar a necessidade de investimentos em abastecimento d'água nestes municípios.

Dos doze municípios do Grupo B incluídos no

TABELA 7. Dados do projeto dos sistemas de abastecimento de água dos municípios do Grupo A.

\begin{tabular}{lccccc}
\hline Município & Manancial & Vazão (1/seg.) & Captação (1/seg.) & Potência (CV) & Adutoras (comprimento) (m) \\
\hline Beberibe & AçudeMalcozinhado & 410,0 & 87,27 & 80,0 & $6.529,7 ; 13.670,7$ \\
Campos Sales & Açude Poço da Pedra & 240,0 & 47,22 & $100,0 / 50,0$ & $32.459,4 ; 9.068,7$ \\
Cascavel & Açude Malcozinhado & 410,0 & 87,27 & 80,0 & $6.529,7 ; 13.670,7$ \\
Groaíras & Rio Acaraú & - & 32,00 & 50,0 & $5.289,8$ \\
Independência & Açude Barra Velha & 380,0 & 10,88 & 40,0 & $11.519,0$ \\
Itapipoca & Açude Gameleira & 480,0 & 99,60 & 300,0 & $19.048,2$ \\
Pindoretama & Açude Malcozinhado & 410,0 & 25,59 & 50,0 & $12.103,1$ \\
Tabuleiro do Norte & Rio Jaguaribe & - & 30,38 & 10,0 & $1.777,1$ \\
Tauá & Açude Trici & 110,0 & 32,00 & & \\
\hline
\end{tabular}

Fonte: Elaborada pelos autores com base nos dados da Agencia Nacional de Águas, 2006. 
Atlas, apenas sete têm informações relacionadas aos projetos necessários para implantação do sistema de suprimento de água (TAB. 7). Neste grupo, todos os mananciais são representados por açudes, com vazões variando de 100 a 3.530 1/seg. Nesse tipo de manancial, as perdas por evaporação são elevadíssimas e, portanto, devem receber cuidados especiais.

Entre os municípios com maior taxa de evaporação, destacam-se o de Croata, com o Açude Jaburu; e Umirim, com o açude Caxitoré, cujas vazões são de, respectivamente, $3.530,01 / \mathrm{seg}$ e $1.7201 / \mathrm{seg}$., estando acima dos valores médios de parâmetros utilizados para a análise da capacidade de suprimento d'água.

A maioria dos açudes da TAB. 8 tem restrições de qualidade da água, com exceção dos açudes Jaburu, que vai abastecer Croata e açude Aracoiaba, que abastece Ocara. A maior alteração de regime de vazão ocorre no açude Várzea da Volta, (22\%) que abastece Coreaú e Moraújo, justificando um monitoramento mais apurado por estarem mais sujeitos a impactos ambientais importantes.

TABELA 8. Dados do projeto do sistema dos Sistemas de Abastecimento de água dos municípios do Grupo B.

\begin{tabular}{lccccc}
\hline Município & Manancial & Vazão (1/seg.) & Captação (1/seg) & Potência CV & Comprimento da Adutora (m) \\
\hline Assaré & Açude Canoas & 220,0 & 5,89 & 25,0 & $12.736,7$ \\
Coreaú & Açude Várzea Volta & 100,0 & 22,00 & 15,0 & $* *$ \\
Croatá & Açude Jaburu I & $3.530,0$ & 281,33 & $300 ; 300 ; 60 ; 500$ & $* *$ \\
Martinópole & AçudeMartinópole & 190,0 & 16,10 & 20,0 & $10.170,5$ \\
Massapê & Açude Acar-Mirim & 550,0 & 41,75 & 50,0 & $10.066,8$ \\
Moraújo & Açude Várzea Volta & 100,0 & 22,00 & 15,0 & $* *$ \\
Ocara & Açude Aracoiaba & 1230,0 & 7,93 & 15,0 & $13.136,0$ \\
Umirim & Açude Caxitoré & $1.720,0$ & 75,69 & $100 / 150$ & $* *$ \\
\hline
\end{tabular}

Fonte: Elaborada pelos autores com base nos dados da Agencia Nacional de Águas, 2006.

Com base nos dados da TAB. 9, verifica-se que os municípios pertencentes ao grupo A devem receber investimentos no valor de aproximadamente $\mathrm{R} \$$ 55,3 milhões para infra-estrutura hídrica até 2015 , beneficiando cerca de 216 mil pessoas. Por outro lado, os custos per capita apresentam grandes disparidades, variando de $\mathrm{R} \$ 4.651,00$ em Ubajara para $\mathrm{R} \$$ 0,66 em Tauá.

O valor dos investimentos previstos para Ubajara, é semelhante aos valores dos municípios de Carnaubal, Ibiapina, Tiangua, Viçosa do Ceará, Guaraciaba do Norte, São Benedito e Croata, que representam o sistema integrado da Ibiapaba, o qual utiliza águas do Açude Jaburu.
A cidade de Croatá é a única que está isolada, sendo abastecida por poços subterrâneos, o que pode tornar crítica a sua situação no médio prazo. No entanto, há previsão de incluir esse município no sistema integrado Jaburu I. O valor estimado é de $\mathrm{R} \$ 62,2$ milhões, incluindo a ampliação do sistema já existente e a integração de Croata.

Em Tauá, que pertence a cuja bacia do Jaguaribe I, o valor dos investimentos per capita estão voltados totalmente para a ampliação do sistema de captação de água pois atualmente, existem conflitos pela água decorrentes de assoreamento, irrigação e uso de agrotóxicos. 
Análise do suprimento atual e potencial de água potável para os Municípios cearenses José César Vieira Pinheiro, Rosemeiry Melo Carvalho, Kelly Silva de Freitas

TABELA 9. Custos dos sistemas de abastecimento d'água nos municípios do Grupo A.

\begin{tabular}{|c|c|c|c|c|}
\hline Municípios & Custo do projeto & Custo do sistema & Custo Total & Custo per capita \\
\hline Alto Santo & $212.516,00$ & $3.340 .483,00$ & $3.552 .999,00$ & 652,00 \\
\hline Beberibe & $401.878,00$ & $7.367 .758,00$ & $7.769 .636,00$ & 394,00 \\
\hline Campos Sales & $333.914,00$ & $5.247 .213,00$ & $5.581 .127,00$ & 326,00 \\
\hline Cascavel & $401.878,00$ & $7.367 .758,00$ & $7.769 .636,00$ & 162,00 \\
\hline Groaíras & $90.367,00$ & $1.242 .546,00$ & $1.332 .913,00$ & 238,00 \\
\hline Independência & $101.480,00$ & $1.395 .346,00$ & $1.496 .826,00$ & 145,00 \\
\hline Itapipoca & $567.246,00$ & $25.895 .501,00$ & $264.62 .747,00$ & 545,00 \\
\hline Pindoretama & $156.354,00$ & $2.149 .874,00$ & $2.306 .228,00$ & 338,00 \\
\hline Quixeré & $186.936,00$ & $308.464,00$ & $495.400,00$ & 50,00 \\
\hline Tabuleiro do Norte & $59.330,00$ & $978.896,00$ & $1.038 .226,00$ & 66,00 \\
\hline Tauá & $2.503,00$ & $15.293,00$ & $17.796,00$ & 0,66 \\
\hline Ubajara & $2.514 .402,00$ & $55.309 .132,00$ & $57.823534,00$ & 4651,00 \\
\hline Total & $5.028 .804,00$ & $110.618 .264,00$ & $115.647 .068,00$ & 511,00 \\
\hline
\end{tabular}

Fonte: Elaborada pelos autores com base nos dados da Agencia Nacional de Águas, 2006.

Os dados de Custo per capita de Umirim também são discrepantes em relação aos demais municípios do grupo B. Estudos indicam que a melhor solução para o município é sair do sistema isolado para um sistema integrado ao de Itapajé. No entanto, ainda não se dispõe de projetos para a realização desses sistemas de integração, os quais requerem investimentos voltados para a construção de estação de tratamento, estação elevatória e adutora, todas para bombear e transportar a água tratada. Assim, o valor dos investimentos de $\mathrm{R} \$ 12,6$ milhões previstos para alocação em
Umirim, conforme consta no Atlas da ANA e registrado na TAB. 10, na verdade se refere ao que será investido num sistema que envolve Umirim e Itapajé.

Considerando-se que os municípios do Grupo B são mais populosos, esperaria- que, em termos per capita, os custos dos sistemas de suprimento de água deveriam ser relativamente mais baixos; no entanto, verifica-se que eles são superiores aos investimentos necessários aos municípios do Grupo A, os quais requerem projetos relativamente mais simples. Desse

TABELA 10. Custos dos sistemas de Abastecimento d'água nos municípios do Grupo B.

\begin{tabular}{lcccc}
\hline Municípios & Custo do projeto & Custo do Sistema & Custo Total & Custo Per capita \\
\hline Assaré & $107.661,00$ & $1.480 .336,00$ & $1.587 .997,00$ & 168,00 \\
Coreau & $157.410,00$ & $2.164 .391,00$ & $2.321 .801,00$ & 206,00 \\
Croatá & $1.110 .807,00$ & $61.094 .401,00$ & $62.205 .208,00$ & $8.523,00$ \\
Martinópole & $122.219,00$ & $1.680 .508,00$ & $1.802 .727,00$ & 277,00 \\
Massapê & $151.682,00$ & $2.383 .568,00$ & $2.535 .250,00$ & 132,00 \\
Moraujo & $157.410,00$ & $2.164 .391,00$ & $2.321 .801,00$ & 698,00 \\
Ocara & $144.893,00$ & $1.992 .284,00$ & $2.137 .177,00$ & 339,00 \\
Umirim & $549.033,00$ & $12.078 .736,00$ & $12.627 .769,00$ & $1.255,00$ \\
Total & $2.501 .115,00$ & $85.038 .615,00$ & $87.539 .730,00$ & $1.194,00$ \\
\hline
\end{tabular}

Fonte: Elaborada pelos autores com base nos dados da Agencia Nacional de Águas, 2006. 
modo, atender prioritariamente os municípios do grupo B, além de ser um imperativo social, reveste-se de uma maior exigência financeira.

Desse modo, pode-se afirmar que a expectativa de abastecimento favorável para o ano de 2015 é maior nos municípios do grupo $\mathrm{A}$, dos quais $30 \%$, conforme o Atlas Nordeste de Abastecimento Urbano de Água (2006), encontram-se em situação considerada satisfatória em termos de abastecimento de água potável em suas sedes.

Isto não significa que nesses municípios não sejam necessárias melhorias e expansão nos sistemas de suprimento. O município de Cascavel, por exemplo, tem um sistema considerado satisfatório, mas o rio Choró pode apresentar problemas de qualidade da água no médio prazo devido ao fato de se incluir esse município no sistema integrado com o município de Beberibe. O Canal do Trabalhador atravessa estes dois municípios e foi construído no ano de 1990 em caráter de urgência ${ }^{2}$ para garantir o abastecimento de água de Fortaleza a partir do açude Orós. O canal deverá ser liberado brevemente desta função original devido à construção do canal da integração e este fato poderá ser a verdadeira redenção das populações do semiárido destes municípios - Beberibe e Cascavel - em termos de abastecimento de água.

Quase todos os municípios do grupo A possuem projetos de melhorias dos seus sistemas de suprimento, destacando-se, planos de integração entre sistemas e ampliação dos sistemas existentes (captação, adução e elevação). Por outro lado, os municípios do grupo B encontram-se em condições não satisfatória de oferta de água até 2015.

Embora alguns municípios do grupo B tenham grande disponibilidade de recursos hídricos, ou seja, alta acumulação de água, caso de Ocara, Croata e Umirim, falta infraestrutura de captação e adução que permita uma distribuição eficiente da água acumulada, além de não contarem com nenhum projeto de investimentos nestes municípios. A disponibilidade e capacidade de armazenamento de água é condição necessária para a existência de um bom sistema de suprimen- to, mas não é condição suficiente. Verifica-se, adicionalmente, que os municípios do grupo $\mathrm{B}$, além de todos os problemas acima mencionados, contam com um menor número de poços que os municípios que compõem o grupo A.

\section{CONCLUSÕES}

A ação planejada no âmbito dos recursos hídricos, principalmente aquelas voltadas para o abastecimento humano, é de importância estratégica para os municípios cearenses. Em geral, um pequeno ajuste nos componentes do sistema, podem ter um grande impacto no sistema global.

A gestão dos sistemas de suprimento de água é mais descentralizada nos municípios do grupo $\mathrm{A}$, os quais apresentam também menor freqüência nos conflitos pelo uso da água. A principal causa de conflitos pelo uso da água em todos os municípios pesquisados, independente de pertencerem ao Grupo A ou B, é o assoreamento dos mananciais, principalmente dos açudes.

No entanto, esse problema poderia ser minimizado se fossem alocados mais recursos para a manutenção dos sistemas de abastecimento de água, porém essa possibilidade não é considerada no Atlas da ANA. Merece destaque o fato de que melhorias no sistema de suprimento de água potável, decorrentes das mais diversas razões mencionadas e analisadas, trazem um impacto altamente positivo na qualidade de vida das populações e isto pôde ser atestado pela diferença do IDH dos grupos A e B.

Com relação às perspectivas futuras, muitos municípios do grupo B, com menores IDH, podem não receber investimentos em seus sistemas de abastecimento, em virtude da existência de economia de escala em monopólios naturais como é o caso de sistemas de abastecimento de água. Este critério poderá excluir aproximadamente a metade dos municípios mais pobres incluídos no Atlas da ANA, os quais deveriam receber prioridade na participação dos investimentos desse setor, para que sejam criadas condições favoráveis ao crescimento econômico desses municípios e melhorias nas condições de vida de suas populações. 


\section{REFERÊNCIAS}

AGÊNCIA NACIONAL DE ÁGUAS - ANA. Atlas Nordeste: abastecimento urbano de água. Brasília: ANA, SPR, 2006.

CAMPOS, N; STUDART, T. Gestão de Águas-Princípios e Práticas. Porto Alegre: M\&M Buss Assessoria Gráfica Digital: ABRH, 2001.

CAPRA, F. Alfabetização Ecológica. Meio Ambiente no Século 21. Coordenação de André Trigueiro. 4 ed., Campinas: Editora Autores Associados, 2005.

CAIRNCROSS, S. Evaluación como Herramienta para el Planeamiento de Abastecimiento de Água en Comunidades Rurales. Centro Internacional de Agua y saneamento. Serie documentos técnicos 15 . OMS. John Wiley \& Sons - Junio 1988.

HENDRIKEN, E. S.; VAN BREDA, M. F. Teoria de contabilidade; São Paulo - 1999

INSTITUTO DE PESQUISA E ESTRATÉGIA ECONÔMICA DO CEARÁ - IPECE. Ceará em Mapas. Informações georreferenciadas e espacializadas para os 184 municípios cearenses. Fortaleza: IPECE, 2009. Disponível em: $<$ http://www2.ipece.ce.gov.br/atlas $>$. Vários acessos.

LIMA, M. G; RIDÃO, P. S. A Cobrança pelo Uso da Água Bruta Rural. In: $47^{\circ}$ CONGRESSO DA SOCIEDADE BRASILEIRA DE ECONOMIA RURAL, Porto Alegre - RS. Anais..., 2008.

MONTEIRO, V. P. Critério para implantação de tecnologias de abastecimento de água potável regiões afetadas pelo alto teor de sal. Dissertação (Mestrado) - Departamento de Economia Agrícola - Centro de Ciências Agrárias UFC; Fortaleza-CE 2002 - 56p.

SEM, A. Desenvolvimento como Liberdade. São Paulo: Companhia das Letras, 2000.

WOULD BANK. Relatório anual de 1999. 